\title{
Hereditary myopathy with lactic acidosis due to ISCU deficiency
}

INSERM

\section{Source}

INSERM. (1999). Orphanet: an online rare disease and orphan drug data base. Hereditary myopathy with lactic acidosis due to ISCU deficiency. ORPHA:43115

Aconitase deficiency is characterised by myopathy with severe exercise intolerance and deficiencies of skeletal muscle succinate dehydrogenase and aconitase. 